\title{
Nicola Di Cosmo, Allen J. Frank, Peter B. Golden (eds). The Cambridge History of Inner Asia. The Chinggisid Age
}

Denise Aigle

\section{(2) OpenEdition}

Journals

Édition électronique

URL : http://journals.openedition.org/abstractairanica/46415

DOI : $10.4000 /$ abstractairanica.46415

ISBN : 1961-960X

ISSN : 1961-960X

Éditeur :

CNRS (UMR 7528 Mondes iraniens et indiens), Éditions de l'IFRI

\section{Référence électronique}

Denise Aigle, « Nicola Di Cosmo, Allen J. Frank, Peter B. Golden (eds). The Cambridge History of Inner Asia. The Chinggisid Age », Abstracta Iranica [En ligne], Volume 37-38-39 | 2018, document 5, mis en ligne le 30 décembre 2018, consulté le 26 septembre 2020. URL : http://journals.openedition.org/ abstractairanica/46415 ; DOI : https://doi.org/10.4000/abstractairanica.46415

Ce document a été généré automatiquement le 26 septembre 2020.

Tous droits réservés 


\title{
Nicola Di Cosmo, Allen J. Frank, Peter B. Golden (eds). The Cambridge History of Inner Asia. The Chinggisid Age
}

\author{
Denise Aigle
}

\section{RÉFÉRENCE}

Nicola Di Cosmo, Allen J. Frank, Peter B. Golden (eds). The Cambridge History of Inner Asia. The Chinggisid Age. Cambridge : Cambridge University Press, $2015^{2}$, xxvii+488 p.

Dans l'introduction du premier ouvrage de cette collection consacrée à l'« Inner Asia » (The Cambridge History of Early Inner Asia) publié en 1990, Denis Sinor écrivait qu'il est difficile de définir clairement les frontières physiques de cette aire culturelle. Il s'agit d'une région de steppes et de déserts où le pastoralisme nomade a été longtemps dominant. Les populations nomadisaient (et nomadisent toujours) dans cet immense ensemble de plaines et de plateaux, surmonté et fragmenté par des massifs montagneux. Les frontières de cet espace sont instables et ont varié dans le temps. L'Asie mineure grecque fut intégrée dans l'Eurasie centrale lorsqu'elle fut occupée par les Huns au V $\mathrm{V}^{\mathrm{e}}$ siècle avant Jésus-Christ et sous les Seldjoukides au $\mathrm{XI}^{\mathrm{e}}$ siècle. La Chine du Nord en fit partie avec l'occupation des Kitan, des Jürchen, des Mongols et des Mandchous. Dans le continent eurasiatique, il existe une culture spécifique à cette région fondée sur les interactions et les échanges entre nomades et sédentaires.

Le second volume (The Cambridge History of Inner Asia. The Chinggisid Age), publié en 2009 puis en version paperback en 2015, s'inscrit en continuité avec l'ouvrage dirigé par Denis Sinor. Il s'intéresse à l'histoire et à l'héritage de l'empire fondé par Gengis Khan et ses fils incluant son impact sur le monde moderne. Les auteurs étudient l'histoire politique et culturelle de l'Empire mongol, des États gengiskhanides qui lui ont succédé 
et des dynasties non-gengiskhanides qui ont dominé toute l'Eurasie centrale. Du point de vue géographique, la zone couverte par les contributions regroupées dans cet ouvrage s'étend de l'Extrême-Orient jusqu'à l'Europe orientale, sur une période chronologique qui va du début du XII siècle jusqu'à l'établissement de l'hégémonie chinoise et russe à partir du XVI ${ }^{e}$ siècle et jusqu'au XIX ${ }^{e}$ siècle. Les auteurs utilisent les recherches récentes avec des approches nouvelles qui revitalisent les études sur l'Eurasie centrale. Les contributions réunies dans cet ouvrage attestent l'importance d'une région dont le destin moderne a longtemps été occulté par la Chine et la Russie.

\section{AUTEURS}

DENISE AIGLE

UMR 8167 - Orient et Méditerranée 